\title{
Philosophic Reflections on Professional Development Connation of Preschool Teachers
}

\author{
Yanjin Liu \\ Department of Preschool Education, Shaanxi Xueqian Normal University, Xi’an, 710100, China
}

Keywords: Preschool teachers, Professional development, Philosophic reflections

\begin{abstract}
The life of preschool teachers has the generative, integrated, unique and autonomous characteristics. From the perspective of philosophy, the professional development of preschool teachers should recognize the possibility and development of the life of preschool teachers. We cultivate teachers with personal style, and help the preschool teachers to achieve better development through the teachers' learning community.
\end{abstract}

\section{Introduction}

Nowadays, preschool career is developing rapidly. Since the Ministry of Education issued Kindergarten Teacher Professional Standard (Trial) in February 2012. The problem of preschool teachers' professional development has not been divorced from the social and academic circles. Preschool education as the foundation of national education system in the link, the professional development of preschool teachers' use of life philosophy, has important practical value, it can help to improve preschool teachers' professional development consciousness, improve the spirit level, and the possibility of plasticity of children's life development has more profound understanding and interpretation.

\section{Professional Development Connation of Preschool Teachers from Philosophic Perspective}

Before applying the philosophy of life to analyze the professional development of preschool teachers, we must clarify exactly what the real connotation of the professional development of preschool teachers is. In particular, the connotation of the professional development of preschool teachers in the view of life philosophy includes the following aspects.

\subsection{Professional Development of Preschool Teachers from Philosophic Perspective is a Kind of Self Value Recognition}

The traditional teacher professional development is more reflected in a knowledge learning and skill training, that is, learning how to better grasp the rhythm of the classroom and solve the technical problems in the classroom. From the perspective of life philosophy, teachers' development not only attaches importance to knowledge and skills, but also creates a recognition of their professional and professional value in the minds of teachers. This affirmation of his own business is essentially to emphasize the positive perception and positive experience of your own life. This perception and experience will lead to positive professional emotions, and then change into the internal and psychological forces of professional development. When promoting preschool teachers' professional development, we must first consider preschool teachers' attitudes towards their careers, enhance their sense of professional value, cultivate their sense of educational mission, and help preschool teachers find their important significance and value in their work. Especially in the current preschool education in all schools in the lower social status of preschool teachers' personal social value has not yet been widely recognized by the real, so the self-value recognition is the key, it may be appropriate to fill the vacancy and the sense of social value of preschool education spirit of restless world. 


\subsection{Professional Development of Preschool Teachers from Philosophic Perspective is a Kind of Diachronic Process}

Preschool teachers' professional development is not easy, the professional development is a long process, is a through continuous professional training and continuing to the daily teaching experience accumulated gradually improve, and often overlooked is that the preschool teachers, the special nature of its work with - teaching that is teachers should have a rich emotional life education experience, namely the lives of children have a very clear understanding and strong perception and experience, in order to better education for young children. From the perspective of life philosophy, the professional development of teachers is a unique life experience. This is a diachronic process, so teacher professional development is also a process that needs time to digest and understand teaching and life experience. Therefore, the professional development of preschool teachers needs time to nurture and cultivate. The urgent need for quick and instant success requires that the professional development of preschool teachers can be speeded up in a short time, which is not in line with the actual situation. Especially in the view of life philosophy, it is against the growth of human life.

\subsection{Professional Development of Preschool Teachers from Philosophic Perspective is a Kind of the Development of Dual Identity Communion}

Preschool teachers' professional development is not a simple career development, but a comprehensive understanding of their own life as teachers and life as members of society. And this understanding is a dynamic process closely related to their own life growth and life experience. On the one hand, preschool teachers, as educators, have strict rules and regulations for their professional development, and there are certain criteria and evaluation indicators for their professionalism. From this point of view, the professional development of preschool teachers seems to be able to achieve good results through a simple training operation. On the other hand, teachers themselves as members of society, apart from teaching, life experience will have a profound impact on their way of thinking, behavior patterns, and this is engraved on teachers in the subconscious effects schema unconsciously on preschool teachers' professional life, especially the influence of ability for preschool teachers' professional development the attitude, belief, learning cannot be ignored. On the contrary, the perspective of thinking and the way to solve problems in preschool teachers' professional development will also have an impact on their daily life. Therefore, the professional development of preschool teachers is not a simple and professional life, but an intertwined and inextricable development with its daily life. It is also worth noting that the professional particularity of preschool teachers makes the professional life of teachers closely related to the daily life of children. This is also the reason why preschool teachers need more life philosophy than other types of teachers to help early childhood teachers to recognize the difficulties and realities of their professional growth.

\section{Life Attribute of Preschool Teachers from the Perspective of Life Philosophy}

\subsection{Generative Feature of Life}

The professional development of preschool teachers is not a fixed procedure that points to the only result, but an open process with infinite possibilities. This is determined by the life characteristics of preschool teachers. The life of preschool teachers is generative, stochastic and changeable, so the development of preschool teachers is not the only, fixed and mechanical one. The professional development of preschool teachers from the perspective of reality, only the tools of teaching skills and progress, but from a higher spiritual level, the professional development of preschool teachers is to awaken the consciousness of life, let the infinite possibility to realize generative life quality with the professional development open up, preschool teachers' professional development time and content of the teachers' professional development to further expand. 


\subsection{Integration Feature of Life}

Preschool teacher is a kind of social profession, and the person engaged in the work of preschool teacher is also a living individual. The dual attribute of teacher's title determines the existence of two different personalities: the existence of teaching as a profession and the existence of social members in a broad sense. The former emphasizes the professional life of the teacher as a professional, and the latter emphasizes the daily life of the teachers outside the time of teaching. If we can't deal with the relationship between the two ways of life, then the teacher will face the conflict of the different ways of life. We want to help teachers to engage in their own education industry value and their own meaning of life organically, development work for the life of the sense of achievement and happiness, let the children education not only become a simple occupation, and it is a great cause of the pursuit of life, kindergarten teachers' active learning and development mobilize the enthusiasm of the work.

\subsection{Uniqueness Feature of Life}

The uniqueness of teacher's life means that teachers should have individuality and harmony and difference. As far as teachers' professional development is concerned, the professional development of teachers is not uniform and unchangeable because of the uniqueness of teachers' life. For teachers, the contents, goals and methods of their development should also be different. Only in this way, can teachers' personality be formed, teachers' style can be created, teachers' life characteristics can be reflected, and professional development and progress can be achieved. Preschool teachers' life requires teachers to fully explore the uniqueness of teachers' life itself elements in the professional development, the professional development did not become like the factory batch manufacturing mode, character and characteristics of teachers' personal spending, let every one of the kindergarten teachers' professional development eventually become the embodiment of their personal and unique educational wisdom.

\subsection{Autonomy Feature of Life}

In reality, the autonomy of preschool teacher's life is often obscured, which makes its development rely more on external thrust. In the process of the professional development of teachers, teachers often lack the right to speak, the development of the content and evaluation standards are defined by the other except teachers, leading to its development seems to be a complete external regulations task activity, to grasp some concepts of knowledge, learning a kind of teaching means and so on, did not excite the teachers want to improve the inner strength. In this way, the autonomous development of life is distorted into an extraneous development, and the impulse of life is misinterpreted as an external tool requirement. Such preschool teachers cannot achieve real professional independent development.

\section{Path Reconstruction of Professional Development of Preschool Teachers from the Perspective of Life Philosophy}

\subsection{Recognize the Possibility of Life and Build a New Vision for Professional Development}

Teachers' life has different development possibilities, and the professional development of teachers should also show different patterns. The construction of a new vision for the professional development of preschool teachers is a prerequisite for the professional development of teachers. The simple vision is that people's views on their own development goals and development are the ideal state of preschool teachers' future planning and expectation. First, from the perspective of professional development goals, preschool teachers have the right to choose the development goals that are in line with their expectations. Second, from the content of professional development, the learning content of preschool teachers should be three-dimensional and omni-directional learning. Third, from the evaluation of professional development, the evaluation of preschool teachers should pay more attention to teachers' self-evaluation, in addition to the examination and review of the 
superior departments.

\subsection{Understand the Integrity of Life and Enhance Professional Identity}

At present, preschool teachers' learning in specialized training is more and more targeted. Few people pay attention to whether preschool teachers grow outside their mission goals or whether they develop in the life outside of teaching time. The training of the utility and the subsequent development of the possibility of separation of integrity of the preschool teachers' life in nature, the teachers as to complete the program behavior tool, artificial split preschool teachers' professional life and daily life, lead to teacher's living on the two worlds, the role of the transformation and conflict cannot be avoided. In this regard, preschool teachers should pay attention to the integration of life experience and build confidence in professional life when they are professional development. First, the society should pay attention to the overall survival situation of preschool teachers. When we train and guide preschool teachers, we should not only see the social role of kindergarten teachers, but also see that preschool teachers are the existence of life and a living "human". Second, the professional development of preschool teachers not only needs professional guidance and training, but also needs the necessary support for the whole living environment.

\subsection{Respect the Uniqueness of Life and Cultivate the Personal Style of Teachers}

Every child teacher is unique, all of which is a kind of experience and comprehension of his own existence, that is, the inner impulse, activity and process of the mind. Therefore, when developing preschool teachers' professional development, they should admit and respond to this difference, and create a unique style of preschool teachers, displaying their own life imprints. For the development of preschool teachers, the relevant departments should hold an open attitude, to those who make bold innovations, the personality of the kindergarten teachers praise commend, encourage them according to their actual situation to start learning, stimulate their vitality and creativity, so as to promote the further development of the professional.

\subsection{Strengthen the Autonomy of Life and Build a Learning Community of Teachers}

Human life is not passive or animal like in the simple adaptation of the world, but consciously towards the way of using and transforming the environment, in order to seek better development. First, preschool teachers' learning community can promote preschool teachers' teaching experience and improve teachers' ability to criticize and reflect. In kindergarten teachers' learning community, teachers constantly communicate their problems encountered in teaching and the way to deal with them, so as to expand the overall experience of individual teachers. Second, in the kindergarten teachers' learning community, the frequent interaction and communication between teachers and teachers helps to promote their relationship and relationship. Preschool teachers want to feel happy in professional life, in addition to maintaining a harmonious relationship between teachers and students, more attention should be paid to contact the feelings between the peers. The formation of teachers' mutual help teachers in the community of friendship, is of great significance for the stable psychological balance of individual teachers.

In conclusion, life philosophy as a new method and new standpoint for preschool teachers' professional development has provided new possibilities for promoting the improvement of preschool teachers' professional development. In the view of life philosophy, the whole life of the preschool teacher can be revealed, and its own life impulse is able to manifest itself. By improving the awareness of the life of preschool teachers and the recognition of teachers' self-value, the teachers can help the preschool teachers to better carry out the study of professional development. Of course, All the theories cannot be fully committed to perfection. I hope the enlightenment for such researches.

\section{Acknowledgement}

The paper is the result of the Social Sciences Research Project of Shaanxi named "Investigation and Construction of Professional Ethics of Preschool Teachers of Shaanxi Province" (Grant No. 
2014M13).

\section{References}

[1] Meng Jianwei. Education and Life-Meditation on the Life Philosophy of Education [J]. Educational Research, 2007(9): 3-8.

[2] Cui Hongying. On the Life Connotation of Preschool Music Education [J]. Studies in Early Childhood Education, 2015(6): 62-66.

[3] Gao Wei. From Life Understanding to Life Education Life education towards living [J]. Journal of Beijing Normal University (Social Sciences), 2014(5): 35-42.

[4] Pan Duoling, Xia Cheng. On the Philosophical Basis of Life Education for Preschool Children [J]. Education and Teaching Research, 2016, 30(1): 116-122. 